role that bilateral activists play at the domestic policy level. It seems that the type of questions that Steinberg's has been able to address would benefit from a small-N research design were we could continue to benefit from a mixed methodological approach. One exciting possibility is provided by qualitative comparative analysis (QCA) or fuzzy set methodologies (Ragin 2000). These are logical tools based in Boolean algebra suited for the systematic comparison of small-N case studies. Such strategies allow the integration of desirable characteristics of quantitative and qualitative strategies and make it possible to maintaining the richness and depth of information gathered with qualitative approaches while bringing some of the systematic rigor of quantitative ones. In very general terms, by looking at necessary and sufficient conditions it is possible to obtain standard levels of statistical confidence with a relatively small number of cases. Thus for instance, it would be possible to assess the importance of bilateral activists in a small set of countries with varying degrees of success in their environmental policy programs, without loosing the depth of information gathered through qualitative means.

\author{
Cited References \\ Krishna, A. \\ 2002. Active Social Capital. Tracing the Roots of Development and Democracy. New York: \\ Columbia University Press. \\ Ragin, C. C. \\ 2000. Fuzzy-Set Social Science. Chicago: University of Chicago Press.
}

\title{
Lives of Dust and Water: An Anthropology of Change and Resistance in Northwestern Mexico, by Cruz-Torres, Maria Luz (2004), University of Arizona Press, 325 pp.
}

\section{Reviewed by Anton Daughters, Department of Anthropology, University of Arizona, antondaughters@hotmail.com}

Maria Luz Cruz-Torres began her fieldwork in southern Sinaloa in the late 1980s. Her longstanding relationship with the residents of two rural communities there, fostered over the past decade-and-a-half through repeated visits, is candidly documented and woven into the text of her broad and ambitious study of the political ecology of the region. It is this first-hand element that gives Lives of Dust and Water a refreshingly unselfconscious personal dimension. The book offers not just a critical analysis of Mexican economic policy and the impact of the internationalization of markets, but also very detailed, anecdotal, and personalized narratives that impress upon the reader a flesh-and-blood sense of the struggles undergone by southern Sinaloans in the neoliberal era. In this respect, the book stands as a fine example of mixing analysis with storytelling to make a broader point.

Cruz-Torres describes her study as "the political ecology of human survival in one of the most important ecological regions of Mexico" (6). Specifically, she looks at how global demand for shrimp and agricultural products has affected the communities of El Cerro and Celaya by ushering in, with the support of the Mexican government, large, privately-owned export-oriented companies. The results have been diverse and far-reaching: systematic degradation of the area's natural resources through contamination and overexploitation, diversification of subsistence strategies for local fishermen and farmers, and "the feminization of poverty" (277) as more and more women are forced to rely on wage labor.

Cruz-Torres pays particular attention to what she describes as an escalating cycle of natural resource exploitation. She points out that many locals - once members of the communal ejidos and fishing cooperatives - now form the labor base of commercial agriculture and fishing companies. The inadequate wages paid by these companies have forced cash-strapped workers to seek out alternative means of sustenance. This has inevitably meant growing and catching their own food, ultimately putting further stress on agricultural lands and coastal habitats already buckling from commercial contamination and resource-extraction. Cruz-Torres keenly notes this ill-omened subsistence paradox: "Rural communities such as Celaya and El Cerro must face the contradiction of relying ever more heavily on a natural resource base that is diminishing day by 
Reviews

day.... Their struggle to survive requires that they engage in practices that accelerate the deterioration of the resources on which they most depend" (91).

Throughout the book, Cruz-Torres situates her observations within a historical context, often moving seamlessly from the chronological to the particular to the general. She provides an excellent overview of the history of land and resource struggles in Mexico - including the emergence of ejidos and fishing cooperatives in the early twentieth century - and connects these to the shifting development strategies of the same period. Of particular note is the "modernist" approach of the Porfirio Díaz dictatorship and its parallels to the current situation of southern Sinaloa. The Porfiriato's emphasis on an industrial and commercial expansion driven by foreign capital, Cruz-Torres notes, produced "several unequal and contrasting Sinaloas" (43), ultimately fomenting tension and unrest throughout the state and partly contributing to Mexico's decade of revolutionary violence.

While Cruz-Torres avoids casting long-term predictions, her book implicitly sends out a cautionary note about the future, exhorting the reader to consider the dangers of market-driven natural resource extraction. Beyond this broader theme, though, Cruz-Torres also offers a glimpse of the daily drama of the residents of El Cerro and Celaya. Her stories of love, betrayal, and survival, written in a straightforward and unassuming prose, resonate with the universality of human struggle. It is this last element in particular that elevates Lives of Dust and Water from the theoretically interesting and relevant to the universally poignant.

\section{Political Nature: Environmentalism and the Interpretation of Western Thought, by John M. Meyer (2001), Cambridge: MIT Press, 210 pages.}

\section{Reviewed by Karen Pennesi, Department of Anthropology, University of Arizona. kpennesi@u.arizona.edu}

In this timely book, John Meyer lays the theoretical groundwork for what he terms "political nature". While sympathetic to the goal of environmentalists who seek a more profound consideration of nature in political decision-making, Meyer rejects their "calls for a new "ecological worldview"' (p. 1). Appealing to a vaguely defined concept of nature to direct political and economic actions, Meyer argues, ignores the political judgments involved in determining what is natural, and does not account for variations in interpretation. Instead, Meyer offers his concept of political nature which requires us to examine the factors that link conceptions of nature and social practices. By focusing on experiences of nature as a place, Meyer describes how the notion of political nature emerges from the dialectic between conceptions of nature and of politics. While this is Meyer's conclusion, most of the book is devoted to detailed analyses of prevalent Western views of the relationship between nature and politics. Through his critique, Meyer shows these views ultimately to be unsatisfactory, though he emphasizes the valuable insights gained from each in the development of his theory.

Meyer begins by outlining the two most common interpretations of the nature-politics relationship in the history of Western thought. The first, which he calls the "dualist account", treats nature as completely separate from human culture, including politics. The second account is referred to as "derivative" in that normative theories about ideal political structures and practices are derived from theories of nature. Meyer's criticism of both the dualist and derivative interpretations is that they do not consider how the conceptions of nature and politics mutually influence each other. Meyer discusses these limitations while examining the work of contemporary environmentalist thinkers as well as the writings of prominent philosophers that are cited as the original proponents of these worldviews. As he explores the work of each thinker, Meyer uses an interpretive approach to find evidence of a dualist or derivative orientation, even if this was not an explicit intention of the writer. This allows him to identify patterns throughout history and to find links between what are usually taken to be theoretically opposed perspectives.

The analysis starts in the second chapter with arguments put forth by environmentalists such as Aldo Leopold, Lynn White, Robyn Eckersley and Murray Bookchin, who hold an ecological view of nature as central to the desired worldview from which social and political order should be derived. Despite their apparently dissimilar approaches, Meyer shows them all to share the derivative interpretation of the nature-politics relationship, which suggests that environmental 